\title{
Posterior Fossa Measurements in Patients With and Without Chiari I Malformation
}

\author{
John A. Dufton, Syed Yaser Habeeb, Manraj K.S. Heran, \\ David J. Mikulis, Omar Islam
}

\begin{abstract}
Purpose: To determine if there is a correlation between cerebellar tonsillar descent in patients with and without Chiari I malformation and three skull morphometric measurements: clivus length, anteroposterior diameter of the foramen magnum, and Boogard's angle. Methods: Cerebellar tonsillar descent, clivus length, anteroposterior diameter of the foramen magnum, and Boogard's angle were measured in mid-sagittal T1-weighted magnetic resonance images of 188 patients. The study included 81 patients with Chiari I malformations (CMI). Without identifiable pathology, 107 patients served as a comparison group. Two-sample t-tests were used to assess for significance. A Pearson correlation matrix was constructed to assess the strength of linear dependence between measured parameters for the study population. Results: A negative correlation was found between tonsillar herniation and clivus length ( $\mathrm{r}=-0.30$, $P<0.001)$, while a positive correlation was found between tonsillar herniation and foramen magnum size $(\mathrm{r}=0.15, P=0.0431)$, and Boogard's angle $(\mathrm{r}=0.23, P=0.0014)$. Clivus length was shorter $(P=0.0009)$ in CMI patients $(4.02 \mathrm{~cm} \pm 0.45)$ than comparison patients $(4.23 \mathrm{~cm} \pm 0.42)$. In addition, the anteroposterior diameter of the foramen magnum was wider $(P=0.0412)(3.74 \mathrm{~cm} \pm 0.40$ compared to $3.63 \pm 0.30)$ and Boogard's angle was larger $(P=0.0079)(123.58$ degrees \pm 8.27 compared to 120.62 degrees \pm 6.79$)$ with CMI. Conclusion: A greater degree of cerebellar tonsillar herniation is associated with a shorter clivus length, a wider anteroposterior diameter of foramen magnum, and a wider Boogard's angle.
\end{abstract}

RÉSUMÉ: Mesures de la fosse postérieure chez des patients avec et sans malformation de Chiari de type I. Objectif : Le but de l'étude était de déterminer s'il existe une corrélation entre l'abaissement des amygdales cérébelleuses chez les patients avec et sans malformation de Chiari de type I (MCI) et trois mesures morphométriques du crâne : la longueur du clivus, le diamètre antéropostérieur du trou occipital et l'angle de Boogard. Méthode : L'abaissement des amygdales cérébelleuses, la longueur du clivus, le diamètre antéropostérieur du trou occipital et l'angle de Boogard ont été mesurés sur des coupes sagittales obtenues par résonance magnétique pondérée en T1 chez 188 patients. Quatre-vingt-un patients porteurs d'une malformation de MCI ont été inclus dans l'étude. Cent sept patients sans pathologie identifiable ont servi de groupe témoin. Des test t ont été utilisés pour analyser les données. Une matrice de corrélation de Pearson a été construite pour évaluer la force de dépendance linéaire entre les paramètres mesurés. Résultats : La corrélation entre la hernie amygdalienne et la longueur du clivus était négative $(\mathrm{r}=-0,30 ; \mathrm{p}<0,001)$ et elle était positive entre la hernie amygdalienne et la taille du trou occipital $(r=0,15 ; \mathrm{p}=0,0431)$ et l'angle de Boogard $(\mathrm{r}=0,23: \mathrm{p}=0,0014)$. La longueur du clivus était plus courte $(\mathrm{p}=0,0009)$ chez les patients porteurs d'une MCI $(4,02 \mathrm{~cm} \pm 0,45)$ que chez les patients du groupe témoin $(4,23 \mathrm{~cm} \pm 0,42)$. De plus, le diamètre antéropostérieur du trou occipital était plus grand $(\mathrm{p}=0,0412 ; 3,74 \mathrm{~cm} \pm 0,40$ comparé à $3,63 \pm 0,30)$ et l'angle de Boogard était plus grand ( $\mathrm{p}=0,0079$ ; 123,58 degrés $\pm 8,27$ comparé à 120,62 degrés $\pm 6,79)$ chez les patients porteurs d'une MCI. Conclusion : Un degré plus élevé de hernie amygdalienne cérébelleuse est associé à un clivus plus court, à un plus grand diamètre antéropostérieur du trou occipital et à un plus grand angle de Boogard.

Can. J. Neurol. Sci. 2011; 38: 452-455

A Chiari I malformation (CMI) is defined as extension of the cerebellar tonsils below the foramen magnum into the cervical canal. This definition is also the basis for radiological diagnosis of CMI, with tonsillar herniation of three to five millimetres $(\mathrm{mm})$ being the sole criteria for abnormality ${ }^{1-4}$. Chiari I malformation is characterized by various morphometric abnormalities, including (but not limited to) a smaller posterior cranial fossa (PCF), shortened clivus, and a wider Boogard's angle $2,4-10$. Underdevelopment of the PCF and resultant overcrowding causes inferior displacement of the cerebellar tonsils ${ }^{2,4-10}$. Given the association of PCF hypoplasia with CMI, our study set out to examine if there was a correlation between degree of cerebellar tonsillar herniation and three skull morphometric measurements: clivus length, anteroposterior foramen magnum diameter, and Boogard's angle.

From the Department of Diagnostic Radiology (JAD, OI), Kingston General Hospital, Queen's University; Queen's University School of Medicine (SYH), Kingston; Toronto Western Hospital (DJM), McLaughlin Pavilion, Toronto, Ontario; Department of Radiology (MKSH), Vancouver General Hospital, Children \& Women's Health Centre BC, University of British Columbia, Vancouver, British Columbia, Canada. Received March 8, 2010. Final Revisions Submitted November 19, 2010. Correspondence to: John A. Dufton, Department of Diagnostic Radiology, Kingston General Hospital, Queen's University, 76 Stuart St., Kingston, Ontario, K7L 2V7, Canada. 


\section{METHODS}

This project was approved for ethical compliance by the institutional review board. Mixed methods were used to acquire cases with a suspected diagnosis of Chiari I malformation. Sequential head MRI patient reports between 2005 and 2006 at two hospitals were manually reviewed, searching for the keywords "Chiari malformation" or "tonsillar ectopia", and between 2004 and 2009 from a third hospital using an automated search program for the same keywords. Patients with secondary disorders thought to affect the position of the cerebellar tonsils were not included in this study. As such, patients with tonsillar herniation secondary to posterior fossa disease, hydrocephalus or cerebral mass lesions, basilar invagination, or prior cranial or cervical spinal surgeries, were excluded. A total 81 patients (mean age 42.6 years \pm 13 ; range $20-79$ years) were identified with CMI by an interpreting radiologist and were included in the study. For a comparison group 107 patients (mean age 41.9 years \pm 14.7 ; range $19-76$ years) had no significant pathology noted on their MRI examination. Unlike the comparison group (63 females: 44 males), the CMI group had a significant predominance $(P=0.0301)$ of females (60 females: 21 males). Table 1 summarizes the presenting clinical signs and symptoms for patients in each group. The patient reports of the subjects included in the study were generated from ten different neuroradiologists.

Magnetic resonance images were taken at either $1.5 \mathrm{~T}$ or $3.0 \mathrm{~T}$, depending on the institution. All measurements in this study were made from sagittal T1-weighted images on a PACS

Table 1: Clinical presenting signs or symptoms of all subjects in study $(\mathbf{n}=188) *$

\begin{tabular}{l|c|c}
\hline & Frequency & Percent \\
\hline Headaches & 54 & 28.7 \\
\hline $\begin{array}{l}\text { Ataxia/Dizziness/ } \\
\text { Vertigo }\end{array}$ & 32 & 17.0 \\
\hline Follow-up $\dagger$ & 30 & 16.0 \\
\hline Other & 30 & 16.0 \\
\hline $\begin{array}{l}\text { Facial pain or } \\
\text { paresthesia }\end{array}$ & 20 & 10.6 \\
\hline $\begin{array}{l}\text { Body pain or } \\
\text { paresthesia }\end{array}$ & 17 & 9.04 \\
\hline Vision problems & 16 & 8.51 \\
\hline Seizures & 14 & 7.45 \\
\hline
\end{tabular}

* Note that frequency total is greater than 188 because several patients had more than one sign or symptom; $†$ Follow-up conditions include familial aneurysms, multiple sclerosis, syringomyelia, query spina bifida and one case of cervical spine pain; $\$$ Other conditions include subjects with nausea or vomiting, trauma, hormonal abnormalities, urinary retention, paraplegia, hearing, memory, or speech problems, and those with no provided history workstation, with slice thickness ranging 3-5 $\mathrm{mm}$, and slice spacing ranging 2-10 $\mathrm{mm}$. The task of recording measurements from all the MR images in the study was divided between two unblinded investigators who followed a standardized technique (see Figure) to make the following morphometric measurements: 1) length of clivus (C) from the tip of the basion (B) to the top of the dorsum sellae (DS), 2) the anteroposterior diameter of the foramen magnum (McRae's line - MR) from the basion (B) to the opisthion $(\mathrm{O}), 3$ ) the angle formed between McRae's line and the plane of the clivus (Boogard's angle), and 4) degree of tonsillar descent using a perpendicular line from McRae's line to the most inferior aspect of the cerebellar tonsils.

A two-sample t-test was used to compare the patients with and without CMI. A Pearson product-moment correlation matrix was constructed to assess the strength of linear dependence between tonsillar descent and the other morphological measurements. A $P$ value of less than 0.05 was considered statistically significant. A multivariate linear regression model was built using clivus length as the dependent variable to assess for independent variable collinearity.

\section{RESULTS}

Table 2 shows a summary of all key variables measured in this study, while Table 3 shows the correlation matrix of all measured variables for the entire study population. A negative

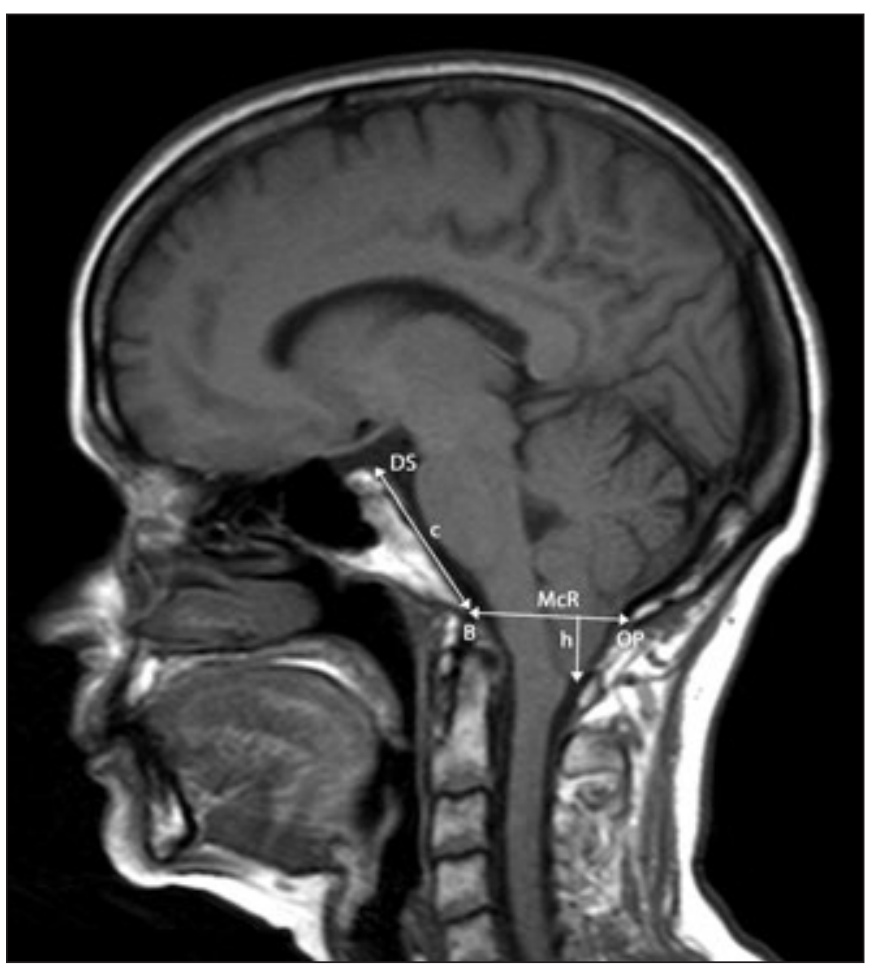

Figure: A T1-weighted sagittal MR image from a subject with Chiari I malformation, showing the midline structures of the posterior cranial fossa, the brainstem, and the cerebellum. McR = McRae's line; $D S=$ top of the dorsum sellae; $B=$ basion; $O P=$ opisthion; $c=$ length of clivus; $h=$ length of tonsillar position relative to McRae's line. 
Table 2: Comparison of basic demographics and measured variables between patients with Chiari I malformation and normal subjects

\begin{tabular}{l|c|c|c}
\hline $\begin{array}{c}\text { Variable } \\
\text { Mean (SD) }\end{array}$ & $\begin{array}{c}\text { CMI group } \\
(\mathbf{n = 8 1 )}\end{array}$ & $\begin{array}{c}\text { Comparison } \\
\text { subjects } \\
(\mathbf{n}=\mathbf{1 0 7})\end{array}$ & P-Value \\
\hline Age & $42.56(12.98)$ & $41.93(14.70)$ & 0.7634 \\
\hline Sex (M/F)* & $25.93 / 74.07$ & $41.12 / 58.88$ & 0.0301 \\
\hline $\begin{array}{l}\text { Tonsillar } \\
\text { position }\end{array}$ & $1.05(0.43)$ & $-0.0019(0.29)$ & $<0.0001$ \\
\hline Clivus length & $4.02(0.45)$ & $4.23(0.42)$ & 0.0009 \\
\hline McRae's line & $3.74(0.40)$ & $3.63(0.31)$ & 0.0412 \\
\hline $\begin{array}{l}\text { Boogard's } \\
\text { angle }\end{array}$ & $123.58(8.27)$ & $120.62(6.79)$ & 0.0079 \\
\hline
\end{tabular}

* Expressed as percentages. Note: lengths in $\mathrm{cm}$ and angles in degrees

correlation was found between clivus length and tonsillar position ( $\mathrm{r}=-0.30, P<0.001)$, while a positive correlation was found between tonsillar position and foramen magnum size $(\mathrm{r}=$ $0.15, P=0.0431)$, as well as between tonsillar position and Boogard's angle ( $\mathrm{r}=0.23, P=0.0014)$. The average clivus length was shorter $(P=0.0009)$ in CMI patients $(4.02 \mathrm{~cm} \pm 0.45)$ than our comparison group $(4.23 \mathrm{~cm} \pm 0.42)$. The average anteroposterior diameter of the foramen magnum was wider $(\mathrm{P}=$ $0.0412)$ in $\mathrm{CMI}$ patients $(3.74 \mathrm{~cm} \pm 0.40)$ than our comparison group (3.63 $\mathrm{cm} \pm 0.30)$. The average Boogard's angle was also found to be wider $(P=0.0079)$ in CMI patients (123.58 degrees \pm 8.27 versus 120.62 degrees \pm 6.79$)$. Average tonsillar herniation was $1.05 \mathrm{~cm} \pm 0.43$ (range $0.52-2.54 \mathrm{~cm}$ ) in subjects with CMI and $-0.0019 \mathrm{~cm} \pm 0.29$ (range $-0.70-0.94 \mathrm{~cm}$ ) in our comparison group. No other significant correlations were found. When the various morphological measurements of the posterior fossa were included in a multivariate linear regression model (with a dependent variable of tonsillar position), both the clivus length variable and the clival-foramen magnum angle maintained their significance; however, the $P$ value foramen magnum size increased to 0.11 . This lack of significance of this variable within this model indicates some element of collinearity with the other independent covariates. The change in the $P$ value for the foramen magnum size was most dramatic with the addition and removal from the model of the clivus length variable indicating the most likely co-variable interaction.

\section{Discussion}

It is well established that overcrowding of the PCF due to PCF hypoplasia leads to cerebellar tonsillar herniation in $\mathrm{CMI}^{2,4-}$ ${ }^{10}$. Given this relationship, the focus of the present study was to examine if there is a correlation between degree of PCF hypoplasia and extent of tonsillar descent. We found a negative correlation between clivus length and degree of tonsillar herniation, and a positive correlation between anteroposterior diameter of the foramen magnum, Boogard's angle, and degree of cerebellar tonsillar herniation, although some collinearity between clivus length and foramen magnum diameter was found, likely due to the related growth and development of posterior fossa. These results contrast with the study by Noudel et $\mathrm{al}^{10}$, which did not find any correlations between the length of basiocciput and tonsillar herniation, or anteroposterior diameter of the foramen magnum and tonsillar herniation. However, the study by Noudel et al did not analyze the entire study population ( $n=47$ ) for correlations, choosing only to focus on the CMI group $(n=17)$. Given the small sample size and the potentially skewed data set due to selective inclusion of only patients with tonsillar descent of at least five $\mathrm{mm}$, the negative finding for correlation may in fact have been a statistical artifact. Indeed, analysis for correlation of the CMI group alone in the present study would yield similar but misleading results.

Table 3: Pearson correlation matrix of measured variables for entire study population $(\mathrm{n}=188)$

\begin{tabular}{|c|c|c|c|c|c|}
\hline & Age & $\begin{array}{l}\text { Tonsillar } \\
\text { position }\end{array}$ & Clivus length & $\begin{array}{c}\text { Foramen } \\
\text { magnum size }\end{array}$ & $\begin{array}{c}\text { Clival-FM } \\
\text { angle }\end{array}$ \\
\hline Age & 1.00 & $-0.0074(0.9194)$ & $-0.13(0.0856)$ & $-0.15(0.0425)$ & $\begin{array}{c}0.15 \\
(0.0445)\end{array}$ \\
\hline $\begin{array}{l}\text { Tonsillar } \\
\text { position }\end{array}$ & $-0.0074(0.9194)$ & 1.00 & $-0.30(<0.0001)$ & $0.15(0.0431)$ & $0.23(0.0014)$ \\
\hline Clivus length & $\begin{array}{c}-0.13 \\
(0.0856)\end{array}$ & $-0.30(<0.0001)$ & 1.00 & $-0.067(0.3621)$ & $-0.36(<0.0001)$ \\
\hline $\begin{array}{l}\text { Foramen } \\
\text { magnum size }\end{array}$ & $\begin{array}{c}-0.15 \\
(0.0425)\end{array}$ & $0.15(0.0431)$ & $-0.067(0.3621)$ & 1.00 & $-0.031(0.6725)$ \\
\hline $\begin{array}{l}\text { Clival-FM } \\
\text { angle }\end{array}$ & $0.15(0.0445)$ & $0.23(0.0014)$ & $-0.36(<0.0001)$ & $\begin{array}{c}-0.031 \\
(0.6725)\end{array}$ & 1.00 \\
\hline
\end{tabular}

Note: P-value given in parentheses 
Other studies have examined the correlation between PCF size and degree of tonsillar herniation but did not address the association between linear morphometric measurements and tonsillar herniation. Vega et $\mathrm{al}^{6}$ and Nishikawa et $\mathrm{al}^{7}$ found no correlation between PCF volume and degree of tonsillar herniation. Schady et $\mathrm{al}^{5}$ found a negative correlation between PCF volume and the degree of tonsillar herniation, while Stovner et $\mathrm{a}^{11}$ found a positive correlation between PCF area and degree of tonsillar herniation. However, the studies by Schady et al and Vega et al did not provide precise measurements of tonsillar descent with degree of herniation only being graded by reference to cervical vertebrae. In concordance with past research ${ }^{2-6,8-10}$, our study confirms the presence of occipital hypoplasia and dysplasia with clivus length being significantly shorter and Boogard's angle being significantly wider in patients with CMI. According to Noudel et al, early underdevelopment of the basiocciput and clivus, as well as premature closure of the sphenooccipital synchondrosis, may result in a shallower PCF and subsequent downward herniation of the PCF contents ${ }^{10}$.

With regards to the anteroposterior diameter of the foramen magnum, our results showed that it was wider in CMI patients than the comparison group. This finding is contrary to other studies that found no difference in the anteroposterior diameter of the foramen magnum between CMI patients and normal patients ${ }^{3,4-6,8}$. Only Aydin et $\mathrm{al}^{9}$ had findings similar to ours, while Noudel et $\mathrm{al}^{10}$ found that the anteroposterior diameter of the foramen magnum was wider in CMI patients, though it did not reach statistical significance. Aydin et al have suggested that as the caudal hindbrain develops normally, downward herniation of the cerebellar tonsils may contribute towards widening of the anteroposterior diameter of the foramen magnum ${ }^{9}$.

The authors acknowledge that this study may be limited by intraobserver or interobserver variations due to our use of two unblinded individuals to record all measurements. Standardized measurement techniques were used to attempt to reduce this potential bias.

\section{Conclusion}

Results from the present study demonstrate that the extent of cerebellar tonsillar herniation in patients with and without CMI is directly associated with degree of PCF hypoplasia. A shorter clivus length combined with a wider foramen magnum and Boogard's angle may affect PCF size, thus contributing towards PCF overcrowding and increased tonsillar herniation. Future morphometric studies should explore the correlation of PCF size with additional skull morphometric parameters, as well as extent of tonsillar herniation.

\section{REFERENCES}

1. Barkovich AJ, Wippold FJ, Sherman JL, Citrin CM. Significance of cerebellar tonsillar position on MR. Am J Neuroradiol. 1986;7 (5):795-9.

2. Milhorat TH, Chou MW, Trinidad EM, Kula RW, Mandell M, Wolpert C. Chiari I malformation redefined: clinical and radiographic findings for 364 symptomatic patients. Neurosurgery. 1997;44(5):1005-17.

3. Meadows J, Kraut M, Guarnieri M, Haroun RI, Carson BS. Asymptomatic Chiari Type I malformations identified on magnetic resonance imaging. J Neurosurg. 2000;92(6):920-6.

4. Sekula RF, Jannetta PJ, Casey KF, Marchan EM, Sekula LK, McGrady CS. Dimensions of the posterior fossa in patients symptomatic for Chiari I malformation but without cerebellar tonsillar descent. Cerebrospinal Fluid Res. 2005;2:11-7.

5. Schady W, Metcalfe RA, Butler P. The incidence of craniocervical bony anomalies in the adult Chiari malformation. J Neurol Sci. 1987;82:193-203.

6. Vega A, Quintana F, Berciano J. Basichondrocranium anomalies in adult Chiari type I malformation: a morphometric study. J Neurol Sci. 1990;99(2-3):137-45.

7. Nishikawa M, Sakamoto H, Hakuba A, Nakanishi N, Inoue Y. Pathogenesis of Chiari malformation: a morphometric study of the posterior cranial fossa. J Neurosurg. 1997;86(1):40-7.

8. Karagöz F, Izgi N, Sencer SK. Morphometric measurements of the cranium in patients with Chiari type I malformation and comparison with the normal population. Acta Neurochir. 2002; 144(2):165-71.

9. Aydin S, Hanimoglu H, Tanriverdi T, Yentur E, Kaynar MY. Chiari type I malformations in adults: a morphometric analysis of the posterior cranial fossa. Surg Neurol. 1973;64(3):237-41.

10. Noudel R, Jovenin N, Eap C, Scherpereel B, Pierot L, Rousseaux P. Incidence of basioccipital hypoplasia in Chiari malformation type I: comparative morphometric study of the posterior cranial fossa. J Neurosurg. 2009;111(5):1046-52.

11. Stovner LJ, Bergan U, Nilsen G, Sjaastad O. Posterior cranial fossa dimensions in the Chiari I malformation: relation to pathogenesis and clinical presentation. Neuroradiology. 1993; 35(2):113-18. 